\title{
Second Law Analysis of Buoyancy Driven Unsteady Channel Flow of Nanofluids with Convective Cooling
}

\author{
Michael Hamza Mkwizu ${ }^{1, *}$, Oluwole Daniel Makinde², Yaw Nkansah-Gyekye ${ }^{1}$ \\ ${ }^{1}$ School of Computational and Communication Science and Engineering, Nelson Mandela African Institution of Science and Technology, \\ (NM-AIST), Arusha, Tanzania \\ ${ }^{2}$ Faculty of Military Science, Stellenbosch University, Saldanha, South Africa
}

Email address:

mkwizum@nm-aist.ac.tz (M. H. Mkwizu), yaw.nkansah-gyekye@nm-aist.ac.tz (Y. Nkansah-Gyekye), makinded@gmail.com (O. D. Makinde)

\section{To cite this article:}

Michael Hamza Mkwizu, Oluwole Daniel Makinde, Yaw Nkansah-Gyekye. Second Law Analysis of Buoyancy Driven Unsteady Channel Flow of Nanofluids with Convective Cooling. Applied and Computational Mathematics. Vol. 4, No. 3, 2015, pp. 100-115.

doi: $10.11648 /$ j.acm.20150403.12

\begin{abstract}
We investigate the combined effects of buoyancy force and convective cooling on entropy generation in unsteady channel flow of water based nanofluids containing Copper $(\mathrm{Cu})$ and Alumina $\left(\mathrm{Al}_{2} \mathrm{O}_{3}\right)$ as nanoparticles. Both first and second laws of thermodynamics are utilised to analyze the model problem. Using a semi discretization finite difference method together with Runge-Kutta Fehlberg integration scheme, the governing partial differential equations are solved numerically. Graphical results on the effects of parameter variation on velocity, temperature, skin friction, Nusselt number, entropy generation rate, irreversibility ratio and Bejan number are presented and discussed.
\end{abstract}

Keywords: Channel Flow, Nanofluids, Buoyancy Force, Heat Transfer, Entropy Generation, Water, Copper, Alumina

\section{Introduction}

The knowledge of buoyancy driven flow and heat transfer in a vertical channel has many significant engineering and industrial applications; for example, geothermal engineering, solar-collectors, petroleum reservoirs, thermal insulation of buildings, nuclear waste repositories, electrical and microelectronic equipments containers. Ostrach [1] and Khalifa [2] presented a review of heat transfer due to natural convection. Yang et al. [3] studied forced convection in a channel with transverse fins. The problem of unsteady natural convection flow between two vertical parallel plates with one plate isothermally heated and the other thermally insulated was numerically studied by Jha and Ajibade [4]. Lee et al. [5] developed a computational model to investigate the cooling effect on the microchip of synthetic jet interacting with a cross-flow in a micro-channel. Meanwhile, engineering applications of conventional heat transfer fluids such as water, ethylene glycol, and engine oil are limited due to their low thermal properties. A potential solution to improve these thermal properties is to add nanoparticles into the conventional fluids, hence forming so-called nanofluids, Choi [6]. Recently, much attention has been paid to this new type of composite material, due to its enhanced properties and behaviour associated with heat transfer. Therefore when applied to heat transfer system, nanofluids are expected to enhance heat transfer compared with conventional liquids. Anoop et al. [7] conducted an experimental investigation into convective heat transfer characteristics, in the developing region of a tube flow, with alumina-water nanofluid. They found that the enhancement of heat transfer coefficient of alumina nanofluids depended on particle sizes and the convective heat transfer coefficient of nanofluids was enhanced with increasing nanoparticle concentration. Khanafer et al. [8] presented a theoretical analysis for buoyancy-driven heat transfer enhancement in a twodimensional enclosure utilizing nanofluids. Abu-Nada [9] reported the application of nanofluids for heat transfer enhancement of separated flow encountered in a backward facing step. Mutuku-Njane and Makinde [10] conducted a numerical study on the effects of magnetic field on nanofluid flow and heat transfer over a permeable vertical plate with convective cooling. Grosan and Pop [11] presented a numerical solution for the problems of fully developed mixed convection in a vertical channel filled with nanofluids.

Moreover, all thermo-nanofluidic processes involve irreversibilities and therefore incur an efficiency loss. In 
practice, the extent of these irreversibilities can be measured by the entropy generation rate. The pioneer work on entropy generation in flow systems was done by Bejan $[12,13]$. He showed that the engineering design of a flow and thermal systems could be improved through minimizing the entropy generation. A lot of literature is available relating to the study of entropy generation effects in pure fluids with different geometrical configurations and situations [14-16]. There are only a few studies that consider the second thermodynamic laws in the presence of nanofluids. The entropy generation and natural convection in a square cavity with a vertical heat source which is filled with copper-water nanofluid was studied by Shahi et al. [17]. They found that the entropy generation decreases with the solid volume fraction. Mahmoudi et al. [18] conducted a numerical study on the entropy generation due to natural convection cooling of a nanofluid in a partially open cavity. Their results showed that the presence of nanoparticles is less effective in enhancement of the Nusselt number and in the reduction of the entropy generation. Makinde et al. [19] numerically studied the entropy production and irreversibility due to flow and heat transfer of nanofluids over a moving flat surface. It was found that the entropy generation can be minimized by appropriate combination of parameter values together with nanoparticles volume fraction.

Mkwizu and Makinde [20] did a research on entropy generation in a variable viscosity channel flow of nanofluids with convective cooling. Results revealed that, general increase in entropy production across the channel with increasing viscous heating, pressure gradient and a decrease in nanofluid viscosity.

The main originality of the present work is the second law analysis due to unsteady natural convection in a vertical channel filled by $\mathrm{Cu}$-water and $\mathrm{Al}_{2} \mathrm{O}_{3}$-water nanofluids in the presence of convective cooling at the channel walls. To the best of authors' knowledge, no such a study which considers this problem has been reported in the literature yet. The numerical analysis has been performed for a wide range of Grashof number, solid volume fraction parameter, Biot number and Eckert number. The results are presented in the form of velocity and temperature profiles, skin friction and Nusselt number, entropy generation and Bejan number. Pertinent results are discussed with the help of graphs and tables.

\section{Mathematical Model}

Consider unsteady laminar flow of viscous incompressible nanofluids containing Copper $(\mathrm{Cu})$ and Alumina $\left(\mathrm{Al}_{2} \mathrm{O}_{3}\right)$ as nanoparticles through a vertical channel. It is assumed that the channel walls exchange heat with the ambient surrounding following the Newton's law of cooling. Take a Cartesian coordinate system $(x, y)$ where $x$ lies along the centre of the channel, $y$ is the distance measured in the normal direction as depicted in figure 1 below;

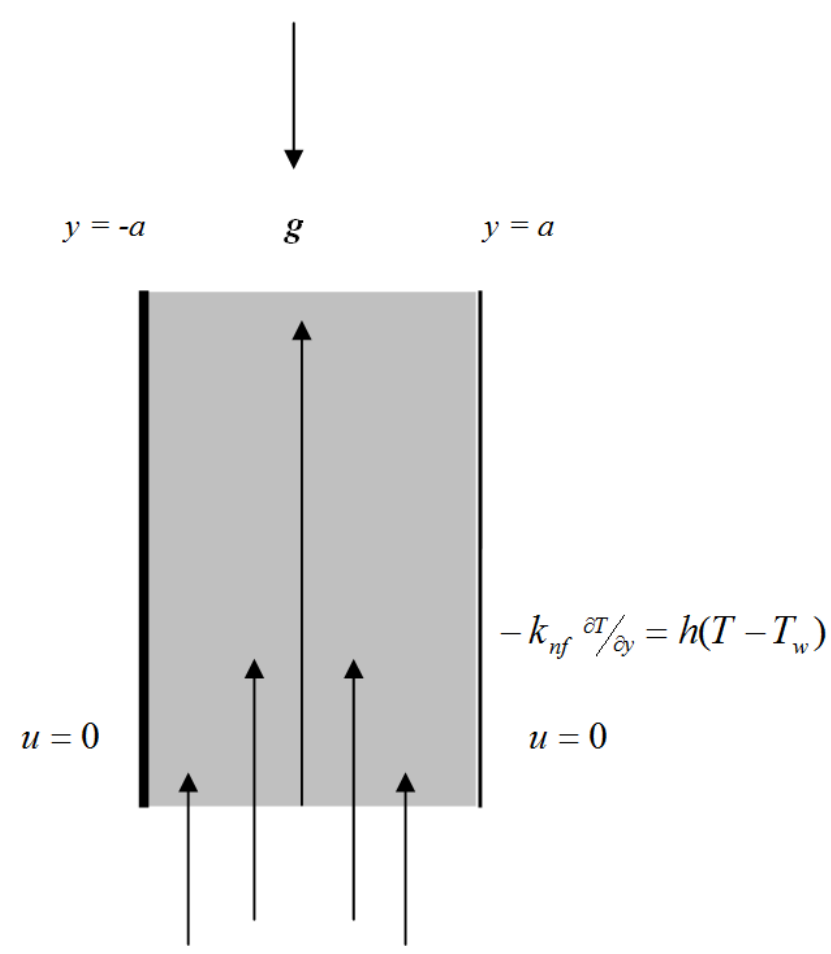

Figure 1. Schematic diagram of the problem under consideration.

In accordance with the Boussinesq approximation, all the fluid properties are assumed to be constant except the density variation with temperature in the buoyancy force term. The Navier-Stokes nanofluids momentum and energy balance equation in one dimension under the Boussinesq approximation for the transient channel flow can be written as

$$
\begin{gathered}
\frac{\partial u}{\partial \bar{t}}=-\frac{1}{\rho_{n f}} \frac{\partial P}{\partial x}+\frac{\mu_{n f}}{\rho_{n f}} \frac{\partial^{2} u}{\partial y^{2}}+\frac{g \beta_{n f}}{\rho_{n f}}\left(T-T_{w}\right), \\
\frac{\partial T}{\partial \bar{t}}=\alpha_{n f} \frac{\partial^{2} T}{\partial y^{2}}+\frac{\alpha_{n f} \mu_{n f}}{k_{n f}}\left(\frac{\partial u}{\partial y}\right)^{2},
\end{gathered}
$$

where $\mathrm{u}$ is the nanofluid velocity in the $\mathrm{x}$-direction, $\mathrm{T}$ is the temperature of the nanofluid, $\mathrm{P}$ is the nanofluid pressure, $\bar{t}$ is the time, $a$ is the channel half width, $T_{w}$ is the ambient temperature, $\mu_{n f}$ is the dynamic viscosity of the nanofluid, $k_{n f}$ is the nanofluid thermal conductivity, $\rho_{n f}$ is the density of the nanofluid, $\beta_{n f}$ is volumetric expansion coefficient of the nanofluids and $\alpha_{n f}$ is the thermal diffusivity of the nanofluid which are given by [8, 9, 17-19]

$$
\begin{aligned}
& \mu_{n f}=\frac{\mu_{f}}{(1-\phi)^{2.5}}, \quad \rho_{n f}=(1-\phi) \rho_{f}+\phi \rho_{s}, \\
& \alpha_{n f}=\frac{k_{n f}}{\left(\rho c_{p}\right)_{n f}}, \tau=\frac{\left(\rho c_{p}\right)_{s}}{\left(\rho c_{p}\right)_{f}}, \frac{k_{n f}}{k_{f}}=\frac{\left(k_{s}+2 k_{f}\right)-2 \phi\left(k_{f}-k_{s}\right)}{\left(k_{s}+2 k_{f}\right)+\phi\left(k_{f}-k_{s}\right)}, \\
& \left(\rho c_{p}\right)_{n f}=(1-\phi)\left(\rho c_{p}\right)_{f}+\phi\left(\rho c_{p}\right)_{s}, \beta_{n f}=(1-\phi) \rho_{f} \beta_{f}+\phi \rho_{s} \beta_{s}
\end{aligned}
$$

The nanoparticles volume fraction is represented by $\varphi(\varphi=$ 
0 correspond to a regular fluid), $\rho_{f}$ and $\rho_{s}$ are the densities of the base fluid and the nanoparticle respectively, $\beta_{f}$ and $\beta_{s}$ are the thermal expansion coefficients of the base fluid and the nanoparticle respectively, $k_{f}$ and $k_{s}$ are the thermal conductivities of the base fluid and the nanoparticles respectively, $\left(\rho c_{p}\right)_{f}$ and $\left(\rho c_{p}\right)_{s}$ are the heat capacitance of the base fluid and the nanoparticle respectively. It worth mentioning that the use of the above expression for $k_{n f}$, is restricted to spherical nanoparticles given by Maxwel [21] and does not account for other shapes of nanoparticles. Also, Brinkman [22] approximation has been employed to approximate the effective viscosity of the nanofluid $\mu_{n f}$ as viscosity of a base fluid $\mu_{f}$ containing dilute suspension of fine spherical particles. The initial and boundary conditions are given as follows:

$$
u(y, 0)=0, T(y, 0)=T_{w},
$$

$$
\begin{gathered}
\frac{\partial u}{\partial y}(0, \bar{t})=\frac{\partial T}{\partial y}(0, \bar{t})=0,(\text { axial-symmetric conditions }) \\
u(a, \bar{t})=0,-k_{n f} \frac{\partial T}{\partial y}(a, \bar{t})=h\left(T(a, \bar{t})-T_{w}\right)
\end{gathered}
$$

where $T_{w}$ is the ambient temperature. Table 1 below presents thermo physical properties of water, copper and alumina at the reference temperature.

Table 1. Thermophysical properties of the fluid phase (water) and nanoparticles $[8,9,17,18]$.

\begin{tabular}{llll}
\hline Physical properties & Fluid phase (water) & $\mathbf{C u}$ & $\mathbf{A l}_{2} \mathbf{O}_{3}$ \\
\hline$c_{\mathrm{p}}(\mathrm{J} / \mathrm{kg} \mathrm{K})$ & 4179 & 385 & 765 \\
$\rho\left(\mathrm{kg} / \mathrm{m}^{3}\right)$ & 997.1 & 8933 & 3970 \\
$\mathrm{k}(\mathrm{W} / \mathrm{m} \mathrm{K})$ & 0.613 & 401 & 40 \\
$\beta\left(\mathrm{K}^{-1}\right)$ & $21 \times 10^{-5}$ & $1.67 \times 10^{-5}$ & $0.85 \times 10^{-5}$ \\
\hline
\end{tabular}

We introduce the dimensionless variables and parameters as follows:

$$
\begin{aligned}
& \theta=\frac{T-T_{w}}{T_{w}}, W=\frac{u a}{v_{f}}, t=\frac{\bar{t} v_{f}}{a^{2}}, v_{f}=\frac{\mu_{f}}{\rho_{f}}, B i=\frac{h a}{k_{f}}, \bar{P}=\frac{\rho_{f} a^{2} P}{\mu_{f}^{2}}, \\
& \left.A=-\frac{\partial \bar{P}}{\partial X}, X=\frac{x}{a}, G r=\frac{\beta_{f} g T_{w} a^{3}}{v_{f}^{2}}, \eta=\frac{y}{a}, \operatorname{Pr}=\frac{\mu_{f} c_{p f}}{k_{f}}, E c=\frac{v_{f}^{2}}{c_{P f} T_{w} a^{2}},\right\} \text {. } \\
& \tau=\frac{\left(\rho c_{p}\right)_{s}}{\left(\rho c_{p}\right)_{f}}, m=\frac{\left(k_{s}+2 k_{f}\right)+\phi\left(k_{f}-k_{s}\right)}{\left(k_{s}+2 k_{f}\right)-2 \phi\left(k_{f}-k_{s}\right)}, n=\frac{\left(1-\varphi+\varphi \beta_{s} \rho_{s} / \beta_{f} \rho_{f}\right)}{\left(1-\varphi+\varphi \rho_{s} / \rho_{f}\right)}
\end{aligned}
$$

The dimensionless governing equations together with the appropriate initial and boundary conditions can be written as:

$$
\begin{gathered}
\frac{\partial W}{\partial t}=\frac{A}{\left(1-\phi+\phi \rho_{s} / \rho_{f}\right)}+\frac{1}{\left(1-\phi+\phi \rho_{s} / \rho_{f}\right)(1-\phi)^{2.5}} \frac{\partial^{2} W}{\partial \eta^{2}}+n G r \theta \\
\operatorname{Pr} \frac{\partial \theta}{\partial t}=\frac{1}{m(1-\phi+\phi \tau)} \frac{\partial^{2} \theta}{\partial \eta^{2}}+\frac{\operatorname{Pr} E c}{(1-\phi)^{2.5}(1-\phi+\phi \tau)}\left(\frac{\partial W}{\partial \eta}\right)^{2},
\end{gathered}
$$

with

$$
\begin{gathered}
W(\eta, 0)=0, \quad \theta(\eta, 0)=0 \\
\frac{\partial W}{\partial \eta}(0, t)=\frac{\partial \theta}{\partial \eta}(0, t)=0 \\
W(1, t)=0, \frac{\partial \theta}{\partial \eta}(1, t)=-m B i \theta(1, t),
\end{gathered}
$$

where $B i$ is the Biot number, $G r$ is the Grashof number, $\mathrm{Pr}$ is the Prandtl number, $E c$ is the Eckert number and $\mathrm{A}$ is the pressure gradient parameter. The quantities of practical interest in this study are the skin friction coefficient $C_{f}$ and the local Nusselt number $\mathrm{Nu}$ which are defined as

$$
C_{f}=\frac{a^{2} \tau_{w}}{\rho_{f} v_{f}^{2}}, \quad N u=\frac{a q_{w}}{k_{f} T_{w}},
$$

where $\tau_{w}$ is the wall shear stress and $q_{w}$ is the heat flux at the channel walls given by

$$
\tau_{w}=-\left.\mu_{n f} \frac{\partial u}{\partial y}\right|_{y=a}, \quad q_{w}=-\left.k_{n f} \frac{\partial T}{\partial y}\right|_{y=a}
$$

Substituting equations (14) into (13), we obtain

$$
\left.\begin{array}{c}
C_{f}=-\frac{1}{(1-\phi)^{2.5}} \frac{\partial W}{\partial \eta} \\
N u=-\frac{1}{m} \frac{\partial \theta}{\partial \eta}
\end{array}\right\} \text { at } \eta=1
$$




\section{Entropy Analysis}

The second law of thermodynamics is an important tool to scrutinize the irreversibility effects due to flow and heat transfer. Thermodynamic irreversibility is closely related to entropy production. Convection process involving channel flow of nanofluids is inherently irreversible due to the exchange of energy and momentum, within the nanofluid and at solid boundaries. Following Woods [14], the local volumetric rate of entropy generation is given by

$$
S^{\prime \prime \prime}=\frac{k_{n f}}{T_{w}^{2}}\left(\frac{\partial T}{\partial y}\right)^{2}+\frac{\mu_{n f}}{T_{w}}\left(\frac{\partial u}{\partial y}\right)^{2}
$$

The first term in equation (16) is the irreversibility due to heat transfer while the second term is the entropy generation due to fluid friction. Using equation (7), we express the entropy generation number in dimensionless form as,

$$
N s=\frac{a^{2} S^{\prime \prime \prime}}{k_{f}}=\frac{1}{m}\left(\frac{\partial \theta}{\partial \eta}\right)^{2}+\frac{B r}{(1-\phi)^{2.5}}\left(\frac{\partial W}{\partial \eta}\right)^{2},
$$

where $B r=E c$ Pr is the Brinkmann number. Let

$$
N_{1}=\frac{1}{m}\left(\frac{\partial \theta}{\partial \eta}\right)^{2}, \quad N_{2}=\frac{B r}{(1-\phi)^{2.5}}\left(\frac{\partial W}{\partial \eta}\right)^{2},
$$

The irreversibility distribution ratio is define as $\Phi=N_{2} / N_{1}$. Heat transfer irreversibility dominates for $0 \leq \Phi<1$ and fluid friction irreversibility dominates when $\Phi>1$. The contribution of both irreversibilities to entropy generation are equal when $\Phi=1$. We define the Bejan numbers $(B e)$ mathematically as

$$
B e=\frac{N_{1}}{N s}=\frac{1}{1+\Phi} .
$$

Equation (19) shows that the Bejan number ranges from 0 to 1 . The zero value of the Bejan number corresponds to the limit where the irreversibility is dominated by the effect of fluid friction while $B e=1$ is the limit where the irreversibility due to heat transfer dominates the flow system. The contribution of both heat transfer and fluid friction to irreversibility are the same when $B e=0.5$.

\section{Numerical Procedure}

The nonlinear initial boundary value problem (IBVP) in equations (8)-(12) are solved numerically using a semidiscretization finite difference method known as method of lines [23]. We partition the spatial interval $0 \leq \eta \leq 1$ into $\mathrm{N}$ equal parts and define grid size $\Delta \eta=1 / N$ and grid points $\eta_{i}=(i-1) \Delta \eta, 1 \leq i \leq N+1$. The discretization is based on a linear Cartesian mesh and uniform grid on which finitedifferences are taken. The first and second spatial derivatives in equations (8)-(9) are approximated with second-order central finite differences.

Let $W_{i}(t)$ and $\theta_{i}(t)$ be approximation of $W\left(\eta_{i}, t\right)$ and $\theta\left(\eta_{i}, t\right)$, then the semi-discrete system for the problem becomes

$$
\begin{aligned}
& \frac{d W_{i}}{d t}=\frac{A}{\left(1-\phi+\phi \rho_{s} / \rho_{f}\right)}+\frac{\left(W_{i+1}-2 W_{i}+W_{i-1}\right)}{\left(1-\phi+\phi \rho_{s} / \rho_{f}\right)(1-\phi)^{2.5}(\Delta \eta)^{2}}+n G r \theta_{i}, \\
& \operatorname{Pr} \frac{d \theta_{i}}{d t}=\frac{\left(\theta_{i+1}-2 \theta_{i}+\theta_{i-1}\right)}{m(1-\phi+\phi \tau)(\Delta \eta)^{2}}+\frac{E c \operatorname{Pr}}{(1-\phi+\phi \tau)(1-\phi)^{2.5}}\left(\frac{W_{i+1}-W_{i-1}}{2 \Delta \eta}\right)^{2},
\end{aligned}
$$

with initial conditions

$$
W_{i}(0)=\theta_{i}(0)=0, \quad, 1 \leq i \leq N+1 .
$$

The equations corresponding to the first and last grid points are modified to incorporate the boundary conditions as follows

$$
W_{2}=W_{1}, \quad \theta_{2}=\theta_{1}, \quad w_{N+1}=0, \quad \theta_{N+1}=\theta_{N}(1-m B i \Delta \eta),
$$

Equations (20)-(22) is a system of first order ordinary differential equations with known initial conditions and can be easily solved iteratively using Runge-Kutta Fehlberg integration technique [23] implemented on computer using Matlab. From the process of numerical computation, the skin-friction coefficient and the Nusselt number in equation (15) are obtained and their numerical values are presented.

\section{Results and Discussions}

Here we considered pure water and two types of waterbased Newtonian nanofluids containing copper $(C u)$ and alumina $\left(\mathrm{Al}_{2} \mathrm{O}_{3}\right)$ as nanoparticles. The Prandtl number of the base fluid (water) is kept constant at 6.2 and the effect of solid volume fraction is investigated in the range of $0 \leq \phi \leq 0.3$. Numerical solution for the representative velocity field, temperature field, skin friction, Nusselt number, Entropy generation rate and Bejan number have been carried out by assigning some arbitrary chosen specific values to various thermophysical parameters controlling the flow system (see figures 2 - 29). The detailed discussion and graphical representation of the results of above equations are reported in this section. 


\subsection{Effects of Parameter Variation on Velocity Profiles}

Figures 2-3 depict the transient effects on the nanofluids velocity profiles. Generally, the velocity increases with time for a given set of parameter values until a steady state profile is achieved as shown in figure 2 . For instance the steady state velocity profile is attained at $\tau=3.5$. Interestingly, the $\mathrm{Al}_{2} \mathrm{O}_{3-}$ water nanofluid tends to flow faster than $\mathrm{Cu}$-water nanofluids as shown in figure 3. This may be attributed to the high density of $\mathrm{Cu}$ nanoparticle as compare to $\mathrm{Al}_{2} \mathrm{O}_{3}$ nanoparticle. Moreover, the velocity profile is parabolic in nature with maximum value along the channel centreline and the minimum value at the walls. Figures 4-7 illustrates the effects of parameter variation on the velocity profiles with $\mathrm{Cu}$-water as the working nanofluid. An increase in nanoparticles volume fraction causes a decrease in the velocity profile as shown in figure 4 . This is expected since the both the density and the dynamic viscosity of the nanofluid increase with increasing nanoparticles volume fraction leading to decrease in the velocity. In figures 5-7, a rise in the nanofluid velocity is observed with an increase in Grashof number, Eckert number and the pressure gradient parameter. As $G r$ increases, the thermal buoyancy effect increases due to temperature gradient, leading to an increase in velocity profile. Similar effect of increasing velocity results from increasing viscous dissipation within the flow system as Ec increases.

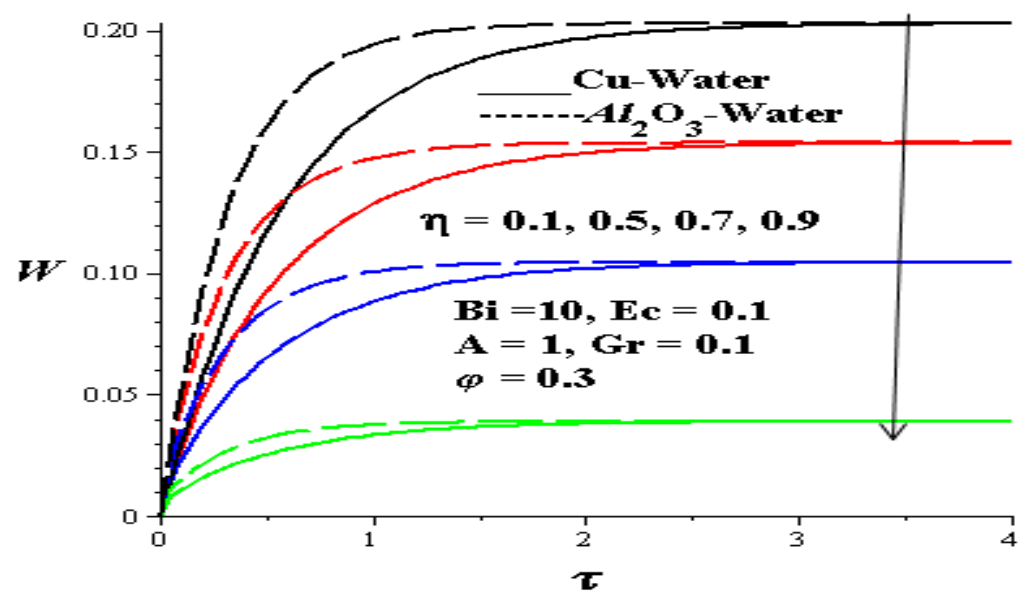

Figure 2. Nanofluids velocity profiles with increasing time.

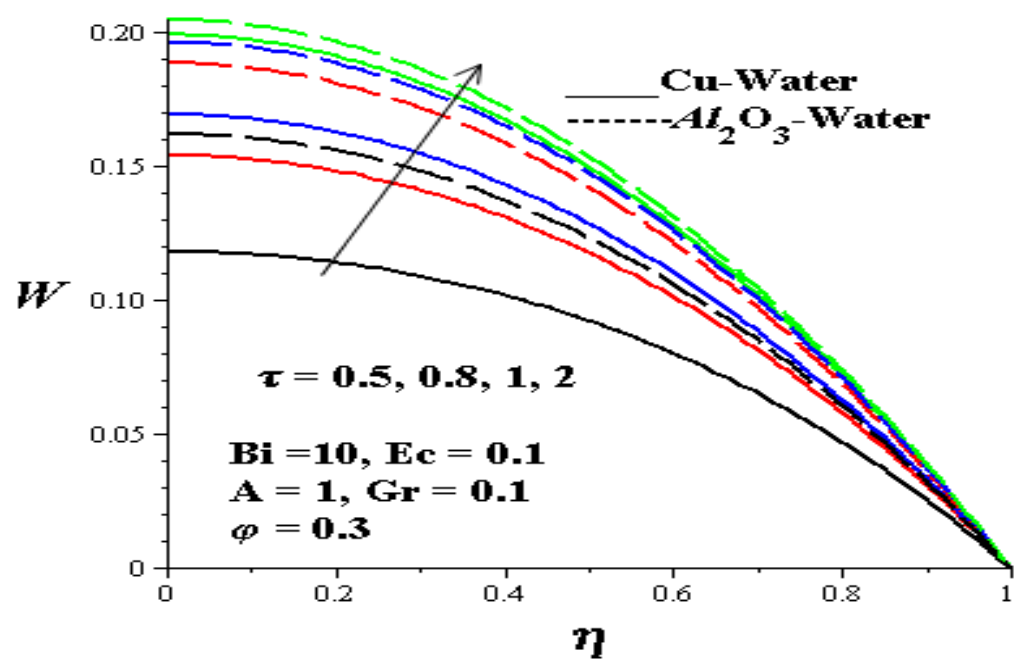

Figure 3. Nanofluids velocity profiles across the channel with increasing time. 


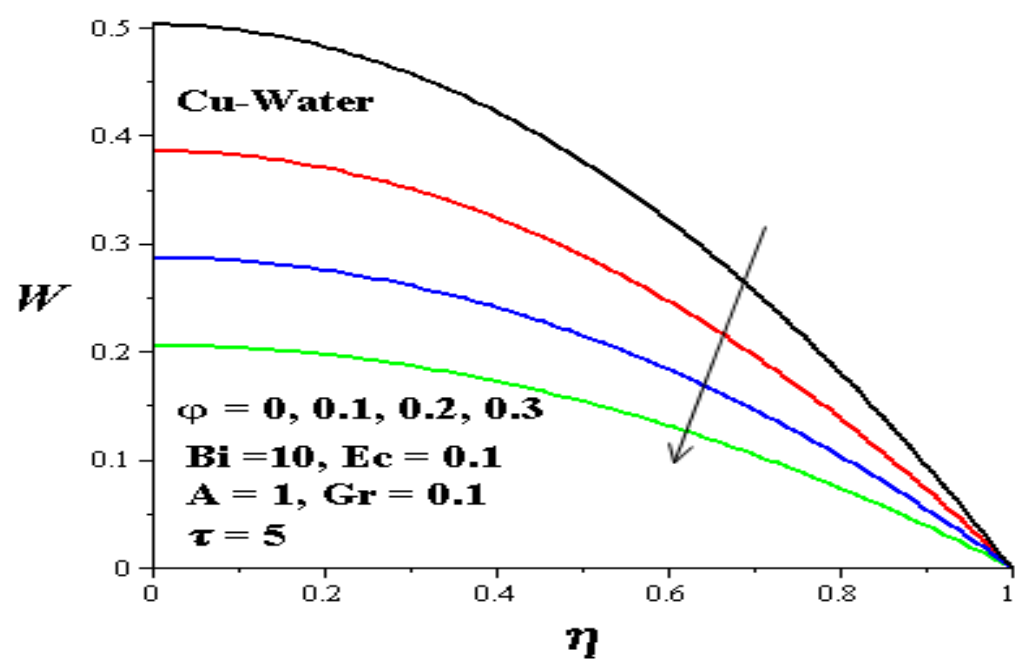

Figure 4. Nanofluid velocity profiles with increasing $\varphi$.

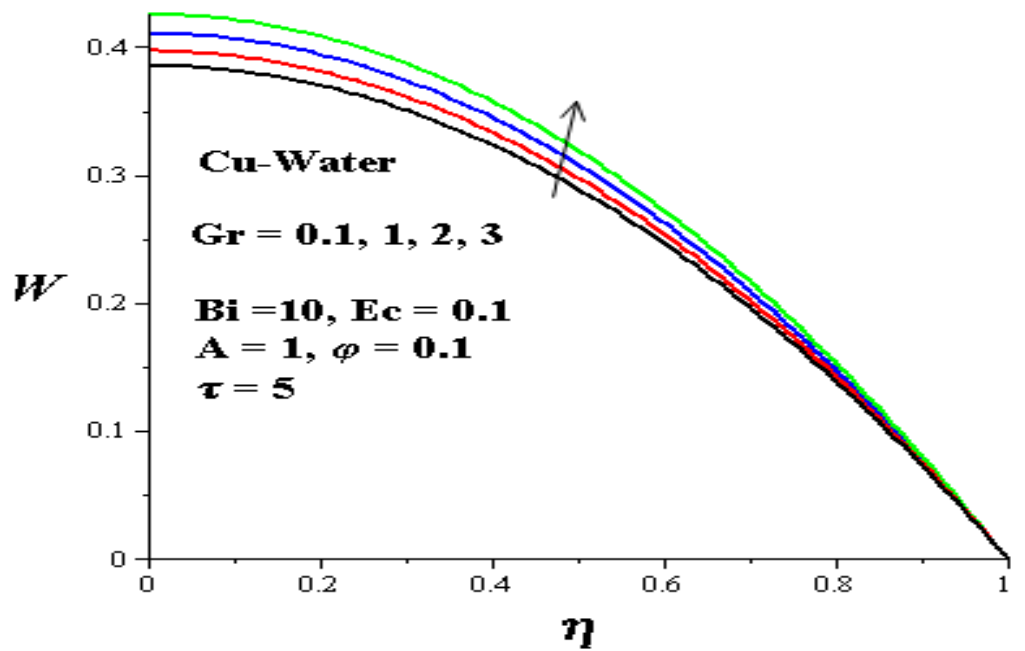

Figure 5. Nanofluid velocity profiles with increasing Gr.

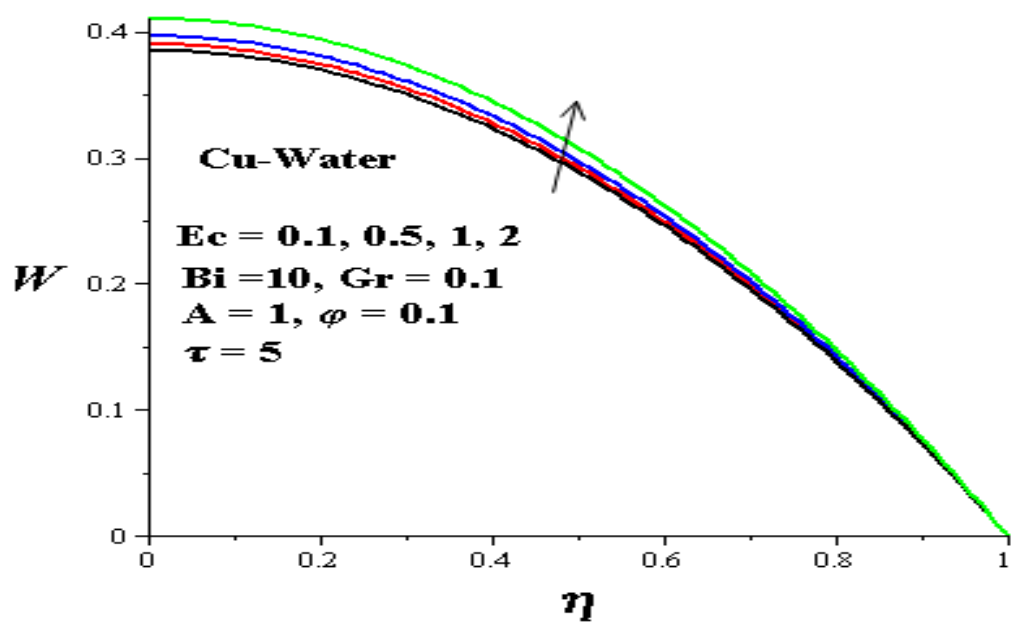

Figure 6. Nanofluid velocity profiles with increasing Ec. 


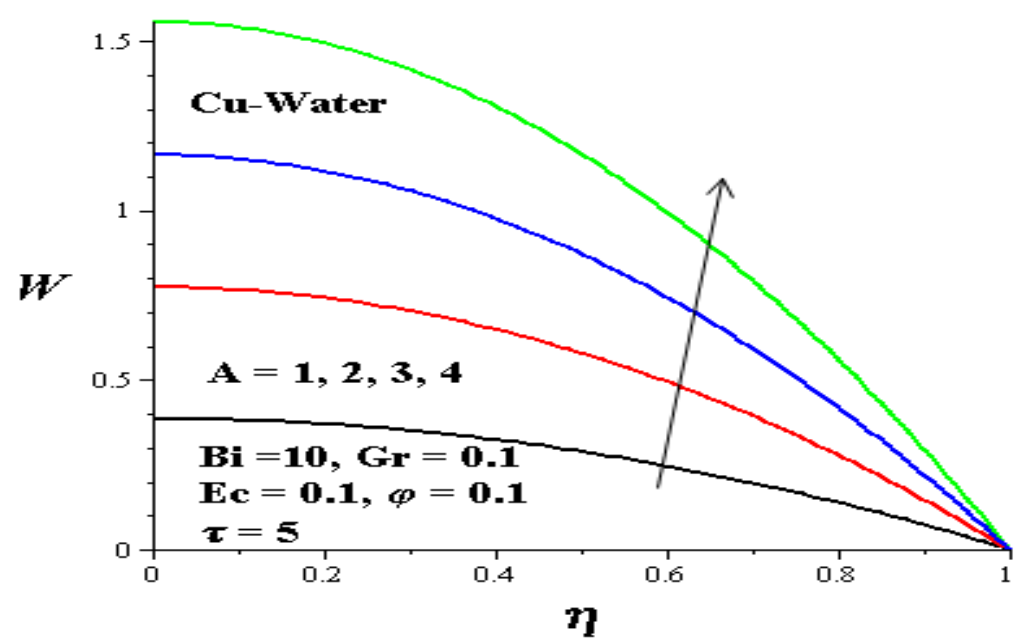

Figure 7. Nanofluid velocity profiles with increasing $A$.

\subsection{Effects of Parameter Variation on Temperature Profiles}

In figures 8-9, the transient effects on the nanofluids temperature profiles are displayed. The temperature increases with time for a given set of parameter values until a corresponding steady state profile is achieved as shown in figure 2. The steady state temperature profile is attained at $\tau$ $=8$. It is noteworthy that the steady state velocity profile is attained earlier than that of temperature profile as shown in figure 8. Interestingly, the temperature of $\mathrm{Al}_{2} \mathrm{O}_{3}$-water nanofluid rises higher than that of $\mathrm{Cu}$-water nanofluids as shown in figure 9. Moreover, the temperature profile attains its maximum value within channel and the minimum value at the walls due to convective heat loss to the ambient. Figures
10-14 illustrates the effects of parameter variation on the temperature profiles with $\mathrm{Cu}$-water as the working nanofluid. As the nanoparticles volume fraction increases, a decrease in the temperature profile is observed as shown in figure 10. Similarly trend of a decrease in temperature is noticed with a rise in Biot number due to a convective cooling at the walls as shown in figure 11. In figures $12-14$, a rise in the nanofluid temperature is observed with an increase in Grashof number, Eckert number and the pressure gradient parameter. This increase in temperature can be attributed to the combined effects of buoyancy force and viscous dissipation.

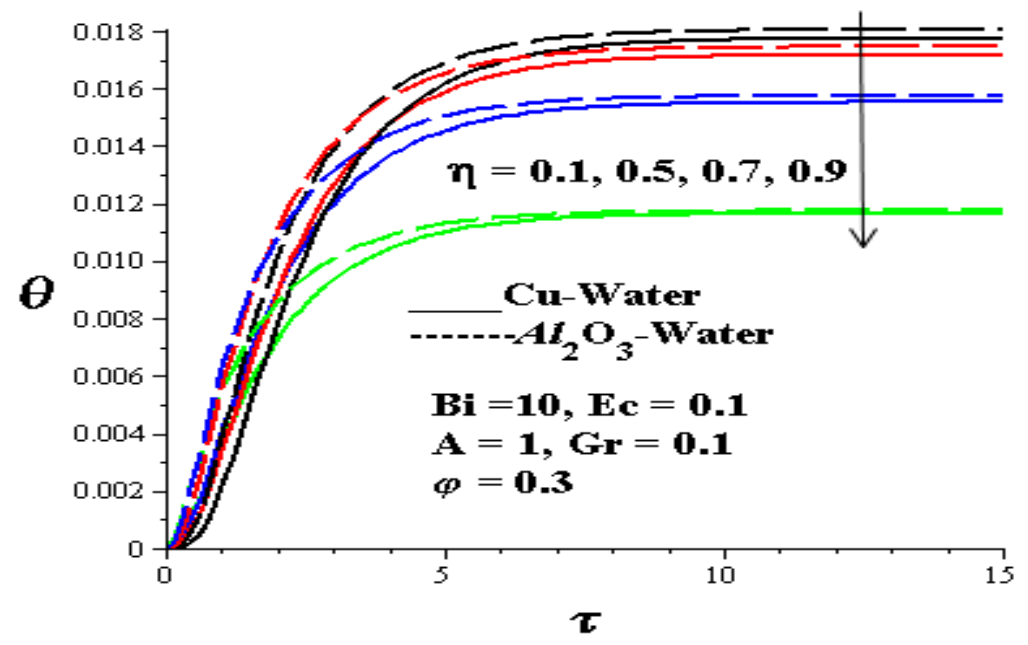

Figure 8. Nanofluids temperature profiles with increasing time. 


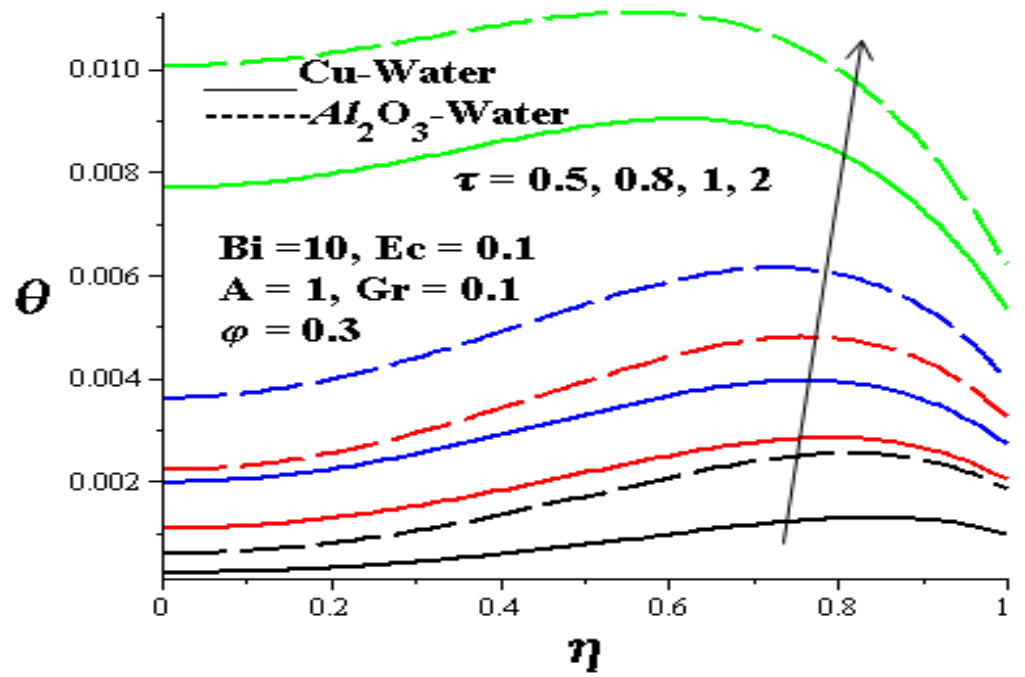

Figure 9. Nanofluids temperature profiles across the channel with increasing time.

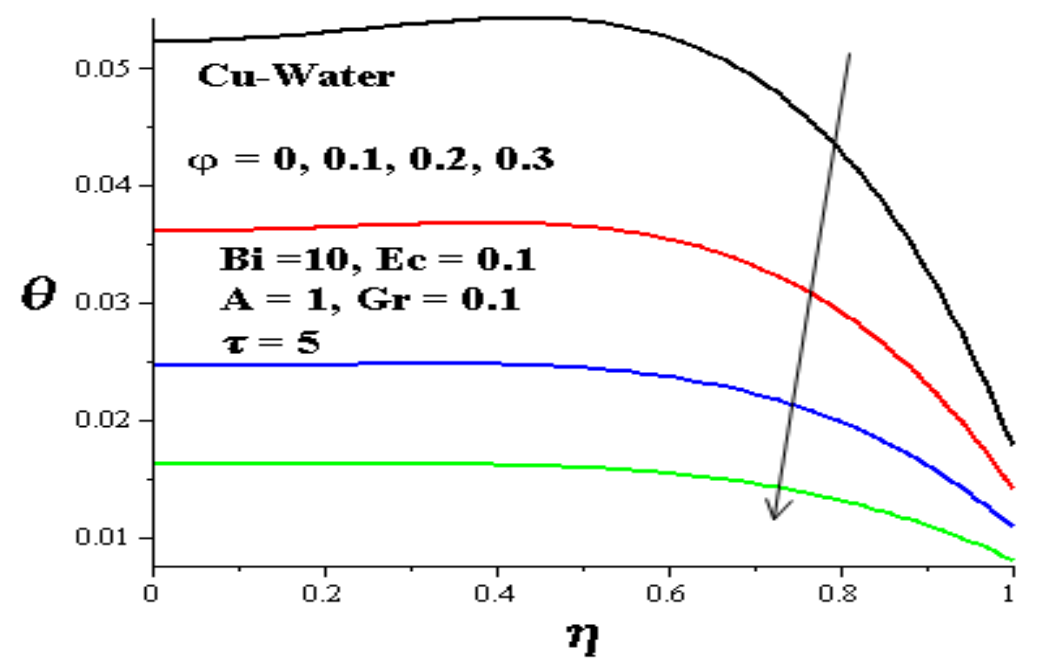

Figure 10. Nanofluid temperature profiles with increasing $\varphi$.

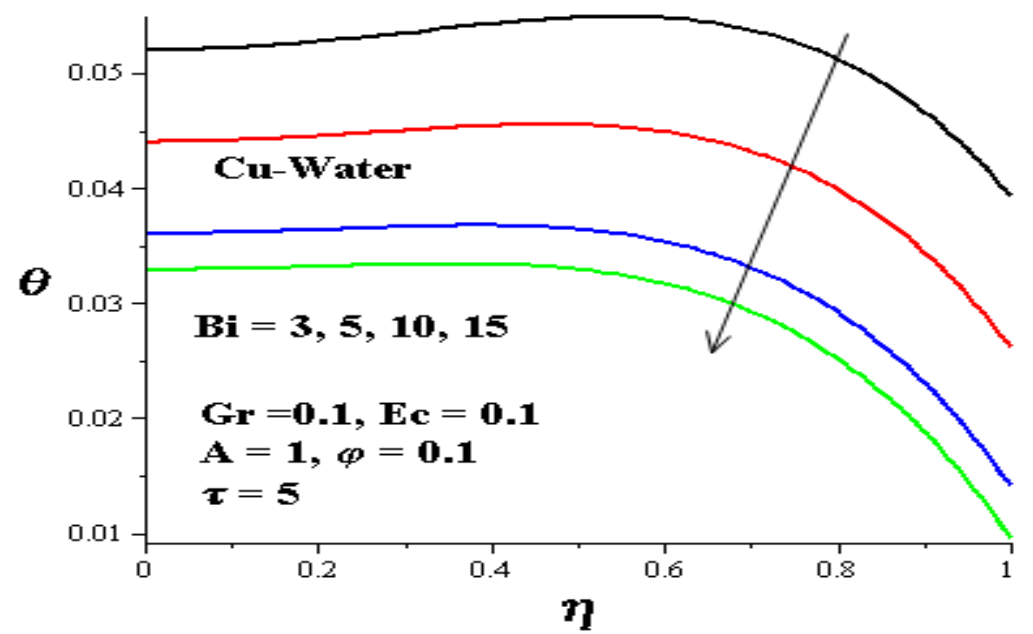

Figure 11. Nanofluid temperature profiles with increasing Bi. 


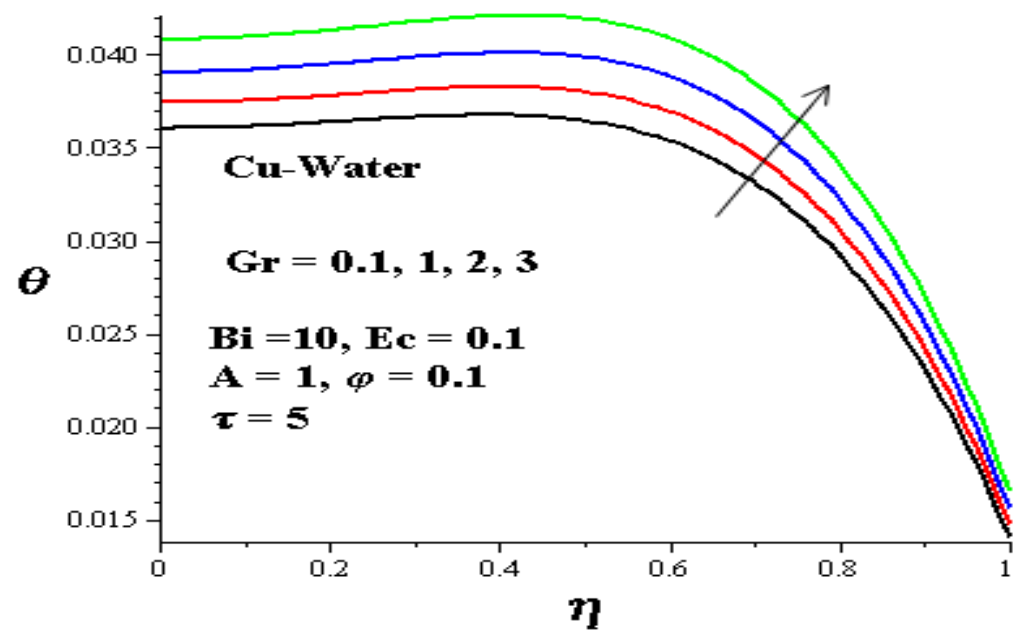

Figure 12. Nanofluid temperature profiles with increasing Gr.

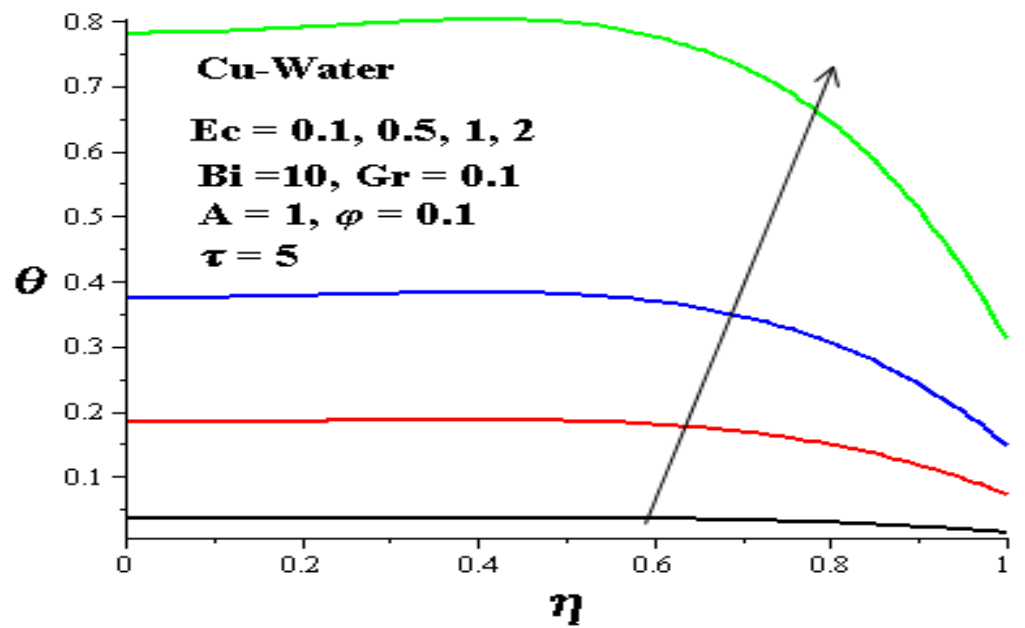

Figure 13. Nanofluid temperature profiles with increasing Ec.

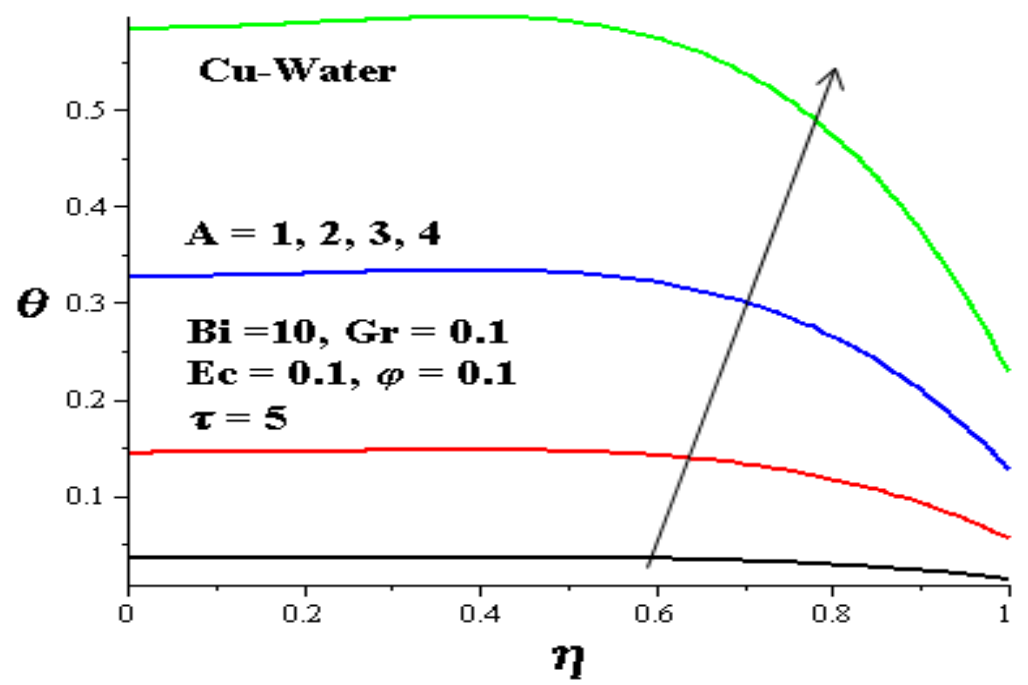

Figure 14. Nanofluid temperature profiles with increasing A.

\subsection{Skin Friction and Nusselt Number}

Figures 15-18 illustrate the effects of parameter variation on skin friction and Nusselt number. In figure 15, it is observed that the skin friction decreases with an increase in nanoparticles volume fraction. This is due to a decrease in the velocity gradient at the channel walls. Moreover, the skin 
friction produced by $\mathrm{Cu}$-water nanofluid is higher than the one produced by $\mathrm{Al}_{2} \mathrm{O}_{3}$-water nanofluid. Interestingly, the skin friction increases with an increase in buoyancy force and viscous dissipation (i.e. Gr, Ec) but decrease with increase in convective heat loss at the walls to the ambient (i.e Bi) as illustrated in figure 16. Figure 17 shows that the heat flux at the channel walls decreases with an increase in nanoparticles volume fraction due to a fall in the temperature gradient. The Nusselt number produced by $\mathrm{Cu}$-water nanofluid is higher than that of $\mathrm{Al}_{2} \mathrm{O}_{3}$-water nanofluid. Hence, $\mathrm{Cu}$-water may serve as a better heat transfer nanofluid and compare to $\mathrm{Al}_{2} \mathrm{O}_{3}$-water. Meanwhile, the Nusselt number increases with an increase in buoyancy force and viscous dissipation but decrease with increase in Biot number as illustrated in figure 18. This may be attributed to an increase or a decrease in the temperature gradient at the walls with a rise in parameter values.

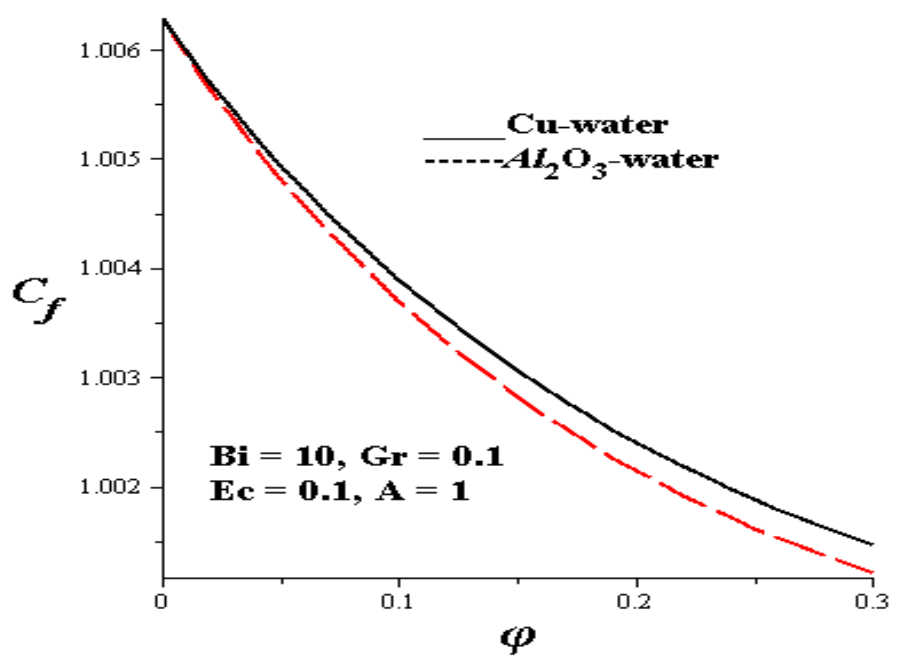

Figure 15. Skin friction with increasing $\varphi$.

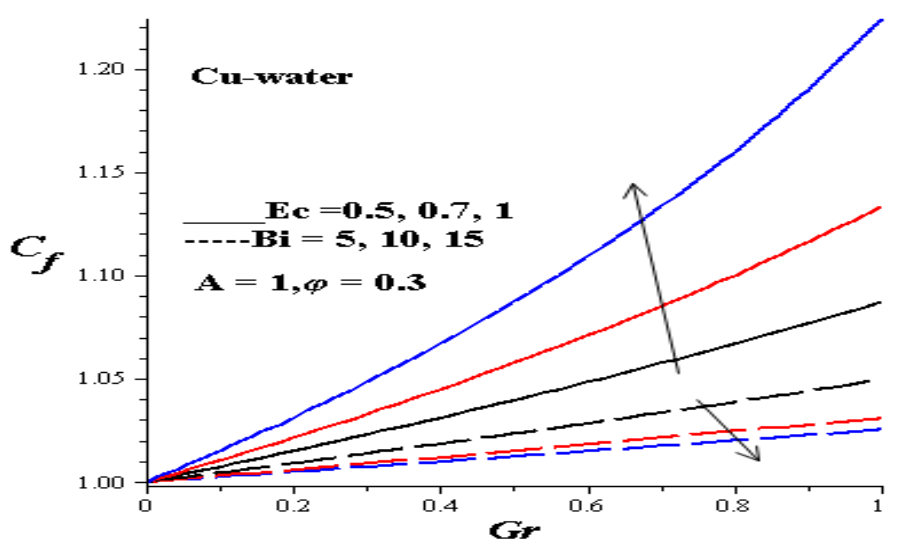

Figure 16. Skin friction with increasing $G r, E c, B i$.

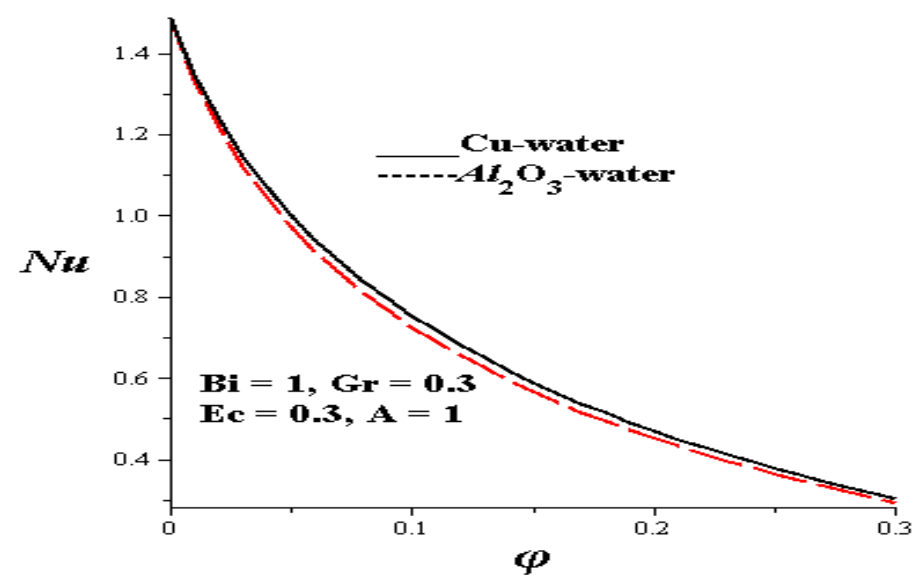

Figure 17. Nusselt number with increasing $\varphi$. 


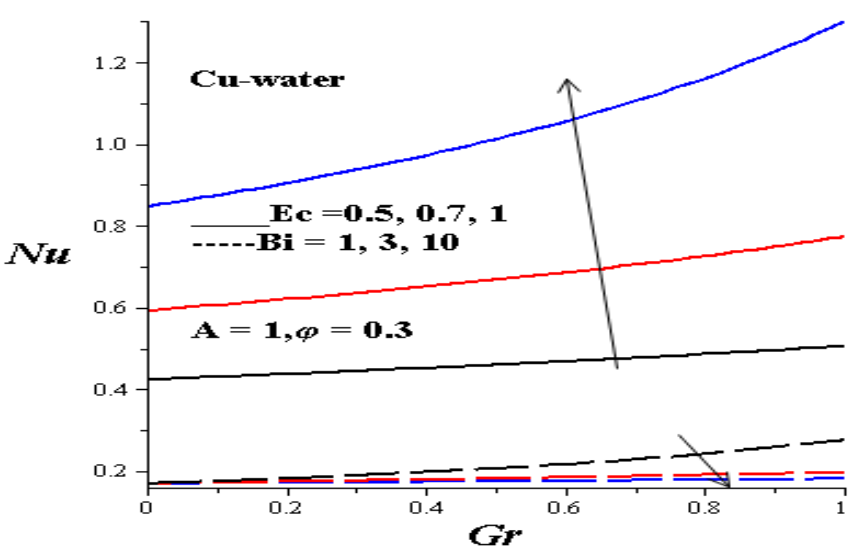

Figure 18. Nusselt number with increasing Gr, Ec, Bi.

\subsection{Effects of Parameter Variation on Entropy Generation Rate}

Figure 19 depicts the transient effect on the entropy generation rate across the channel. The entropy production increases with time for a given set of parameter values. Interestingly, the entropy generated by $\mathrm{Al}_{2} \mathrm{O}_{3}$-water nanofluid is higher than that of $\mathrm{Cu}$-water nanofluids as shown in figure 19. Generally, minimum entropy is produced along the channel centreline region due to the zero velocity and temperature gradients, however, the entropy production increases towards the channel walls. A fall in entropy generation rate is observed with an increase in nanoparticles volume fraction and Biot number as shown in figures 20-21. This is due to the fact that both velocity and temperature gradients within the channel decrease as $\varphi$ and Bi increases. Figures 22-24 show that the entropy generation rate increases with increasing parameter values of $\mathrm{Gr}, \mathrm{Ec}$ and $\mathrm{A}$. Both velocity and temperature gradients increase as the buoyancy force, viscous dissipation and pressure gradient increase, leading to a rise in entropy production.

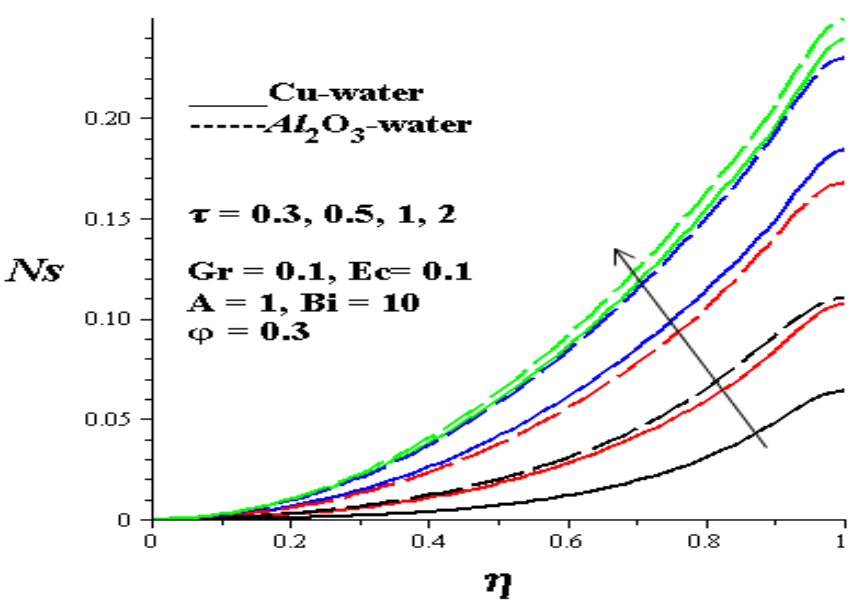

Figure 19. Entropy generation rate with increasing time.

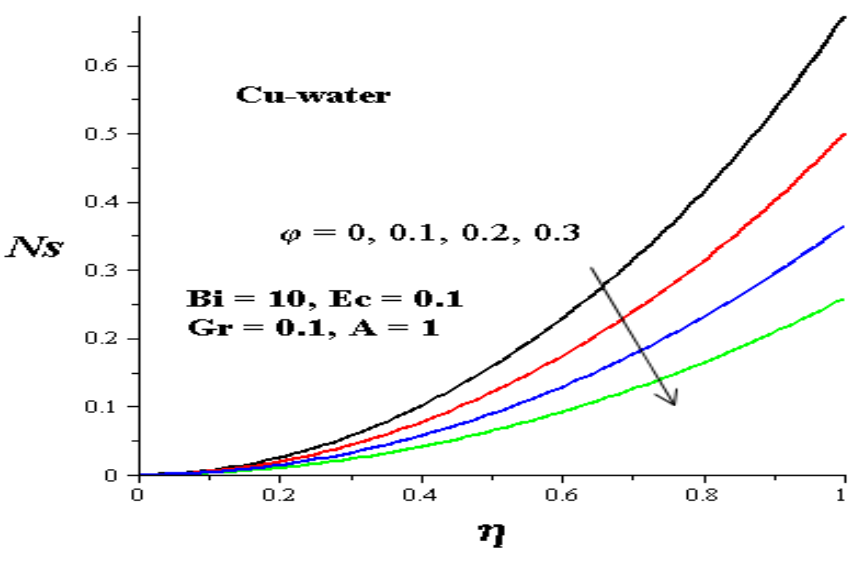

Figure 20. Entropy generation rate with increasing $\varphi$. 


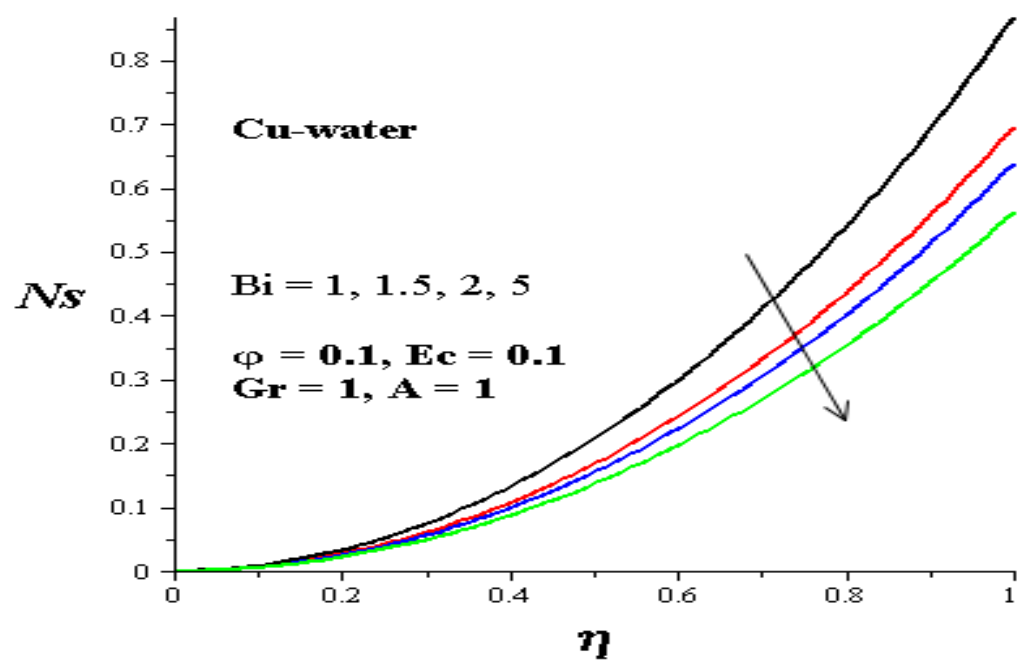

Figure 21. Entropy generation rate with increasing Bi.

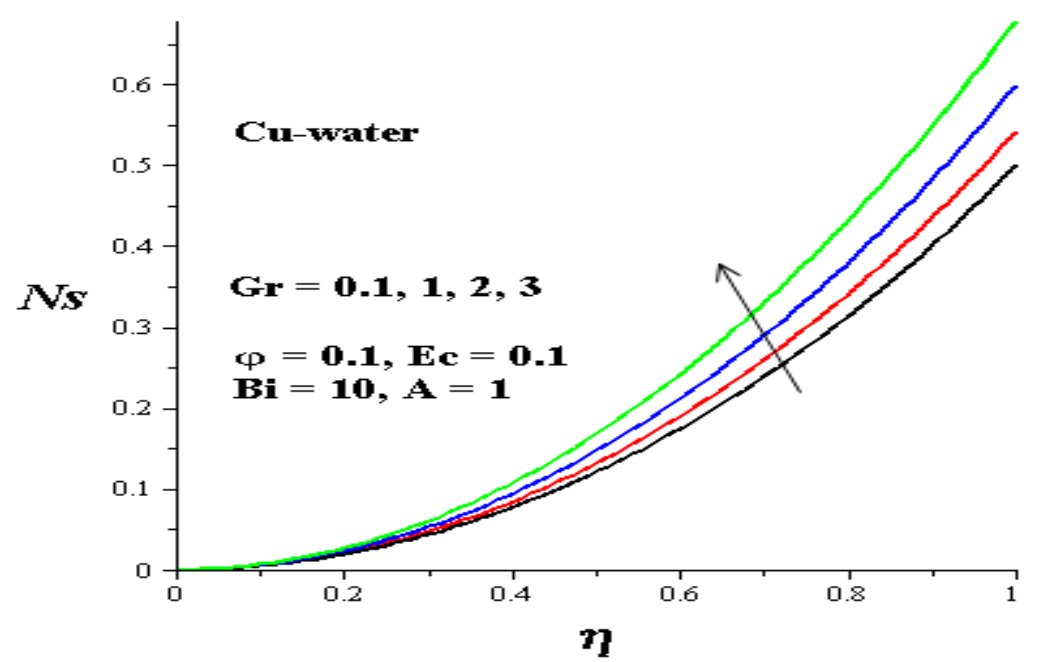

Figure 22. Entropy generation rate with increasing $G r$.

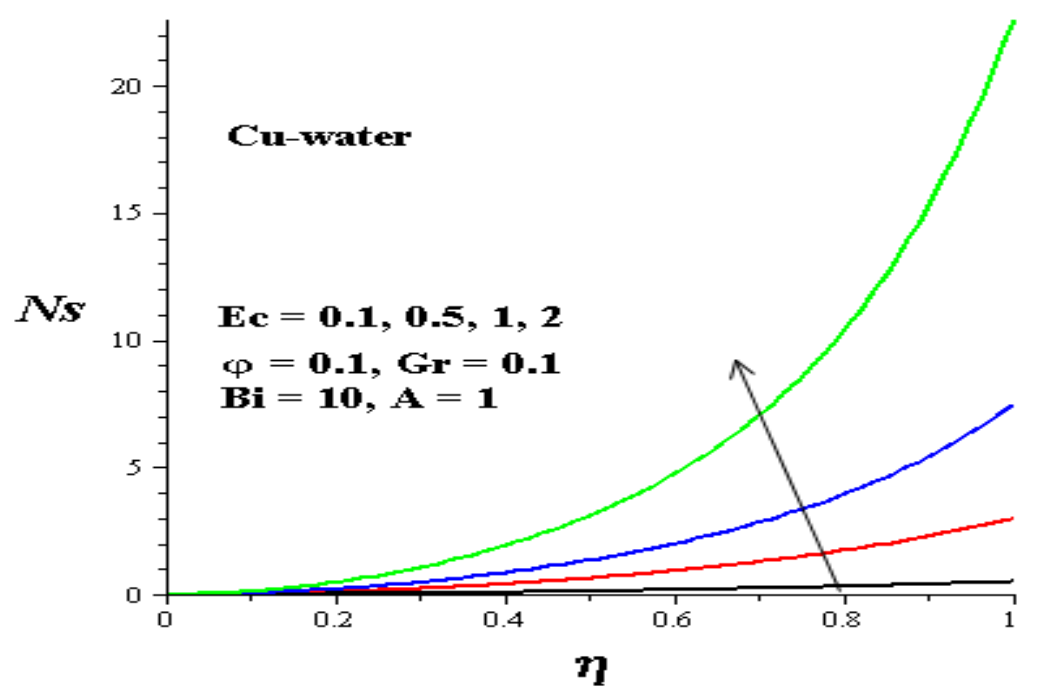

Figure 23. Entropy generation rate with increasing Ec. 


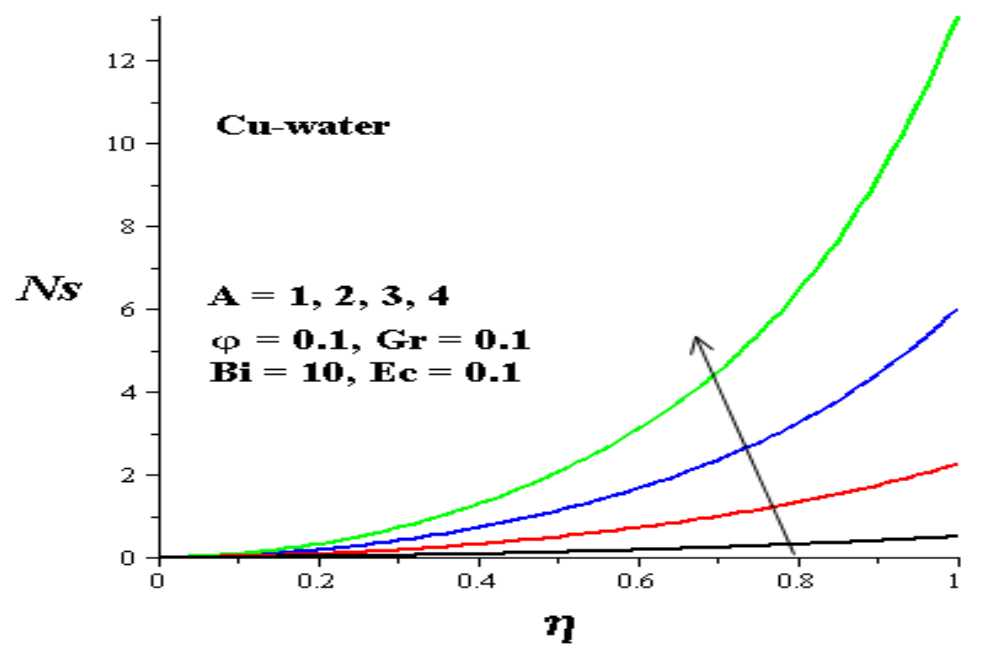

Figure 24. Entropy generation rate with increasing $A$.

\subsection{Effects of Parameter Variation on Bejan Number}

Figure 25 illustrates the transient effect on the Bejan number across the channel. The Bejan number increases with time near the channel walls but decreases near the channel centreline. This can be attributed to a rise in the dominant effect of fluid friction irreversibility within the channel centreline region and the heat transfer irreversibility at the channel walls. It is interesting to note that the Bejan number produced by $\mathrm{Al}_{2} \mathrm{O}_{3}$-water nanofluid near the walls is higher than that of $\mathrm{Cu}$-water nanofluids. Figures 26-27 show a decrease in Bejan number near the walls with an increase in nanoparticles volume fraction and Biot number. This implies an increase in dominant effects of fluid friction irreversibility as $\varphi$ and $\mathrm{Bi}$ increase. Moreover, as Gr, Ec and A increases, the Bejan number near the walls increases leading to a rise in the dominant effects of heat transfer irreversibility as shown in figures 28-30.

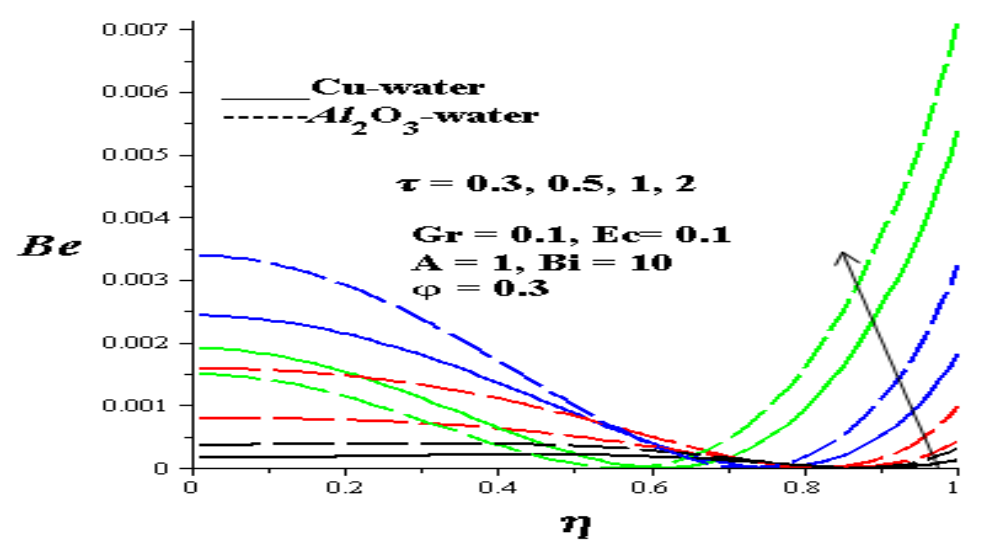

Figure 25. Bejan number with increasing time.

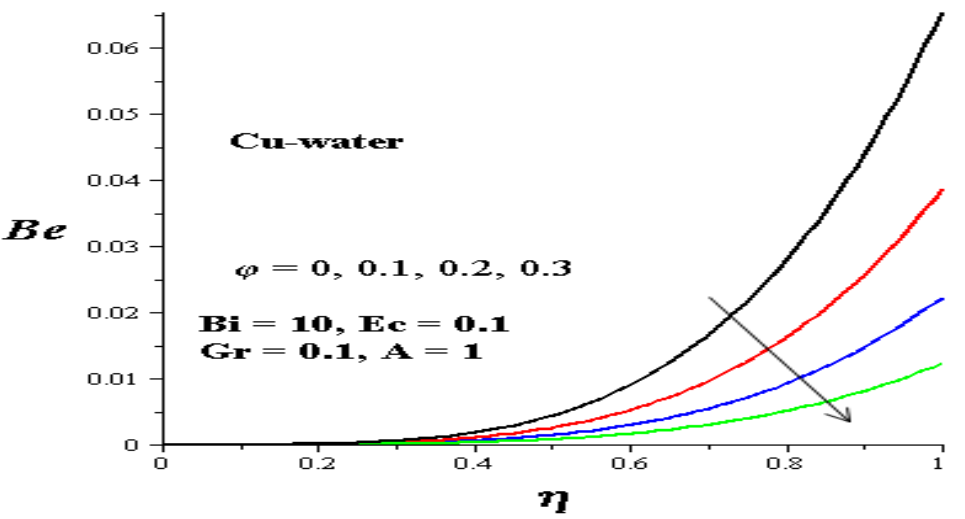

Figure 26. Bejan number with increasing $\varphi$. 


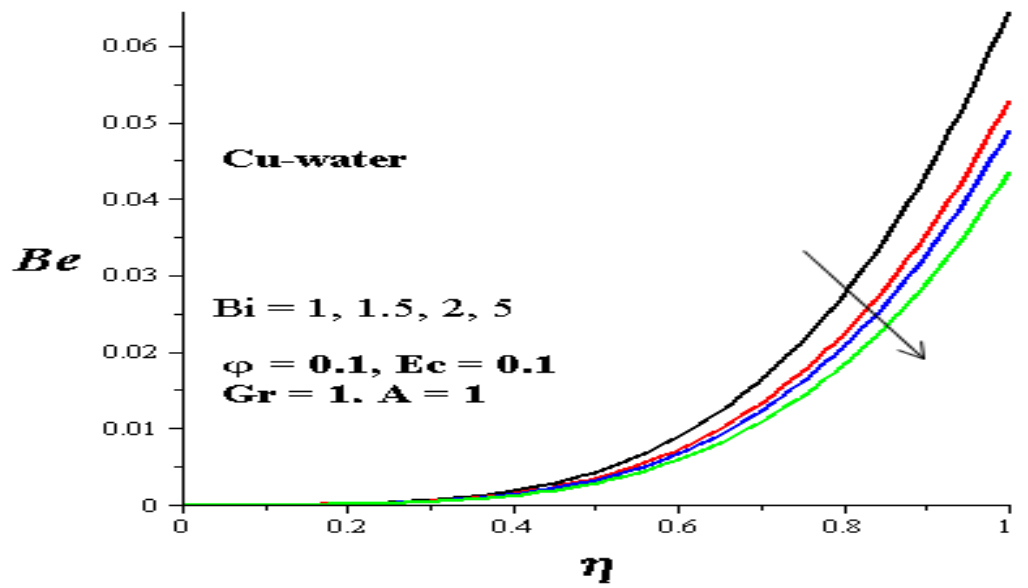

Figure 27. Bejan number with increasing Bi.

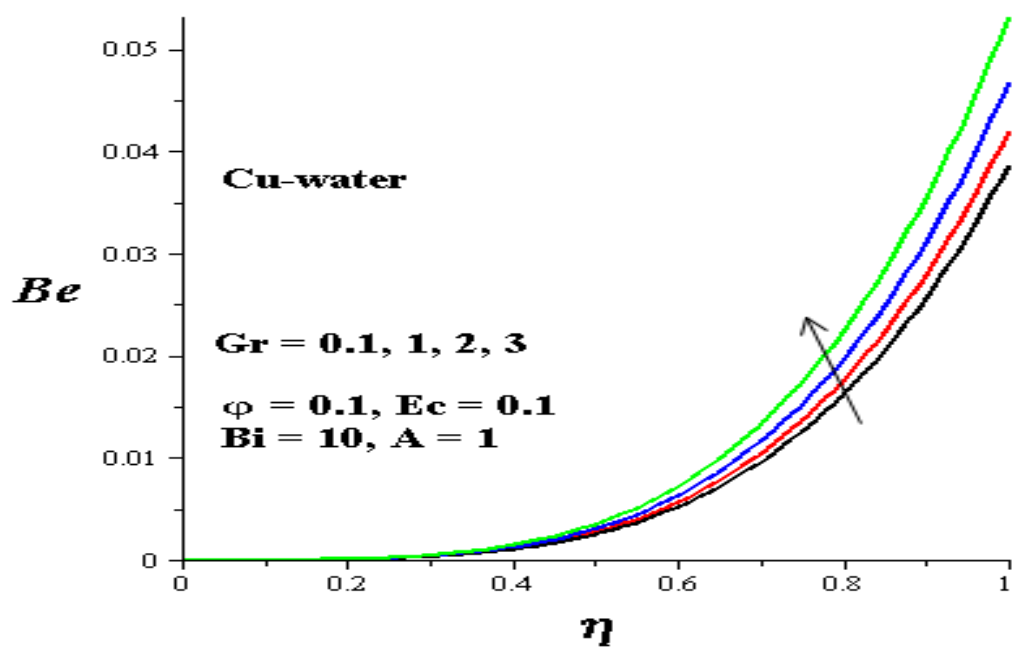

Figure 28. Bejan number with increasing $G r$

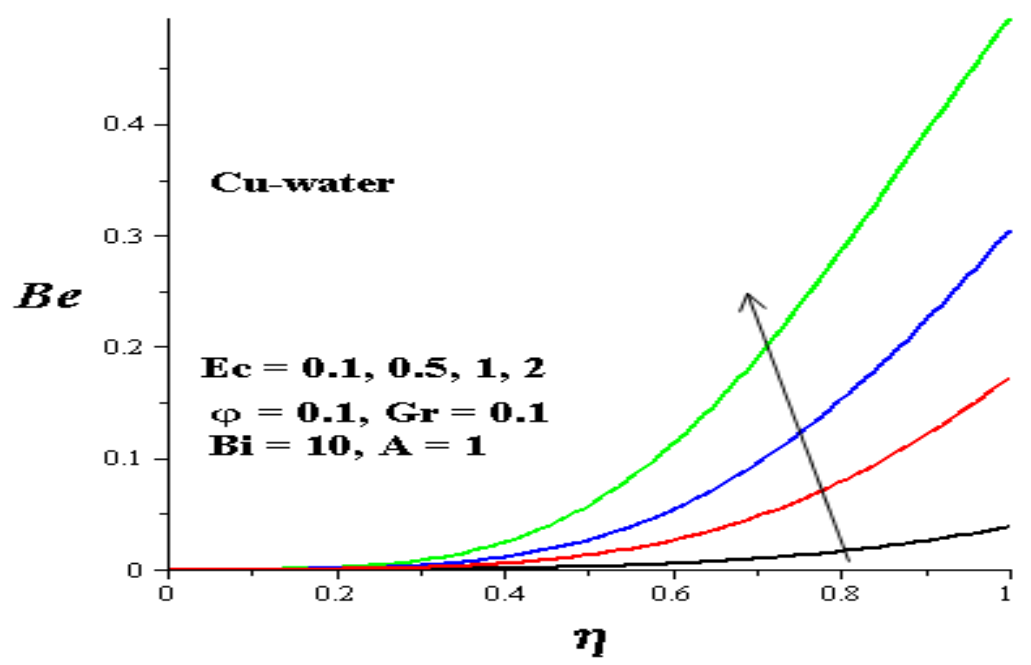

Figure 29. Bejan number with increasing Ec. 


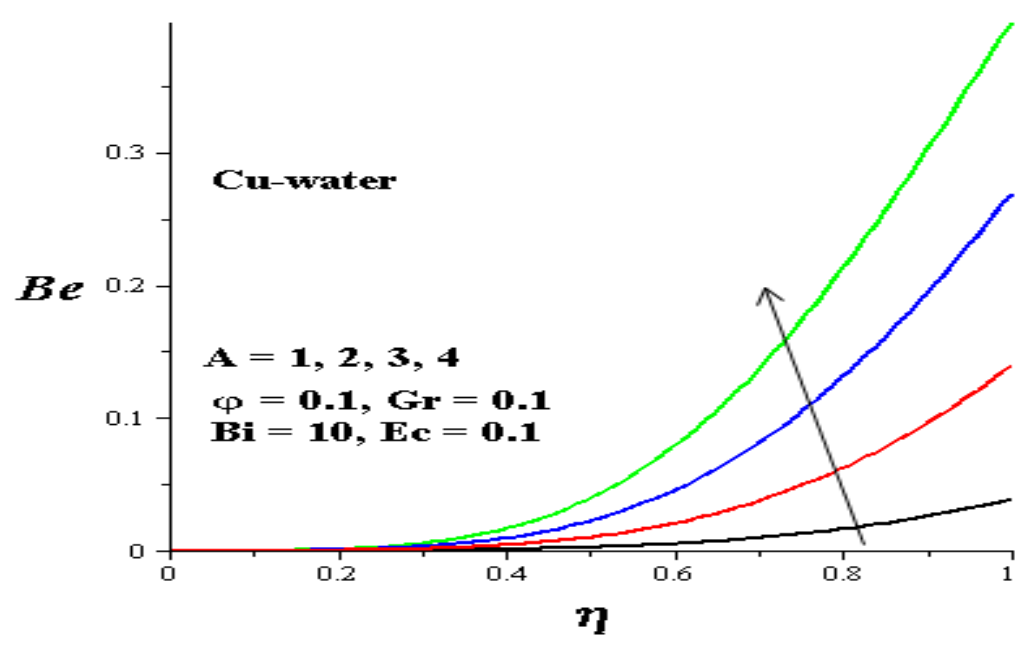

Figure 30. Bejan number with increasing $A$.

\section{Conclusions}

The combined effect of buoyancy force and convective cooling on the unsteady flow, heat transfer and entropy generation rate in a water based nanofluids containing Copper $(\mathrm{Cu})$ and Alumina $\left(\mathrm{Al}_{2} \mathrm{O}_{3}\right)$ as nanoparticles was investigated. The nonlinear governing partial differential equations are solved numerically using a semi discretization finite difference method together with Runge-Kutta Fehlberg integration scheme. Our results are summarised as follows:

- The $\mathrm{Al}_{2} \mathrm{O}_{3}$-water nanofluid tends to flow faster than $\mathrm{Cu}$ water nanofluid and the velocity profile increases with Ec, Gr, A but decreases with $\varphi$.

- The temperature of $\mathrm{Al}_{2} \mathrm{O}_{3}$-water nanofluid rises higher than $\mathrm{Cu}$-water nanofluid and the temperature profile increases with Ec, Gr, A but decreases with $\varphi$ and $\mathrm{Bi}$.

- $\quad$ The $\mathrm{Cu}$-water nanofluid produces higher skin friction than $\mathrm{Al}_{2} \mathrm{O}_{3}$-water nanofluid and the skin friction increases with $\mathrm{Ec}, \mathrm{Gr}$ but decreases with $\varphi$ and $\mathrm{Bi}$.

- The $\mathrm{Cu}$-water nanofluid produces higher Nusselt number than $\mathrm{Al}_{2} \mathrm{O}_{3}$-water nanofluid and the Nusselt number increases with Ec, Gr but decreases with $\varphi$ and Bi.

- The $\mathrm{Al}_{2} \mathrm{O}_{3}$-water nanofluid produces higher entropy than $\mathrm{Cu}$-water nanofluid and the skin generation increases with Ec, Gr, A but decreases with $\varphi$ and Bi.

- Fluid friction irreversibility dominants the channel centreline region while the effects of heat transfer irreversibility near the walls increases with Gr, Ec, A but decreases with $\varphi$ and Bi.

\section{References}

[1] Ostrach, S. (1972) 'Natural convection in enclosures', Advances in Heat Transfer, 8, 161-227.

[2] Khalifa A. J. (2001) 'Natural convective heat transfer coefficient - A review II, Surfaces in two and three dimensional enclosures', Energy Conversion and Management, $42,505-517$.
[3] Yang, M. H., Yeh, R. H., Hwang, J. J. (2012) 'Forced convection in a channel with transverse fins', Int. J. of Num. Methods for Heat \& Fluid Flow, 22, 3, 306 - 322.

[4] Jha, B. K., Ajibade, A. O. (2010) 'Transient natural convection flow between vertical parallel plates: one plate isothermally heated and the other thermally insulated', Journal of Process Mechanical Engineering, 224(4), 247-252.

[5] Lee, A., Timchenko, V., Yeoh, G. H., Reizes, J. A. (2012) 'Forced Convection in microchannel with synthetic jet: effect of operating frequency', ASME, 10th Int. Conf. on Nanochannels, Microchannels, and Minichannels, Rio Grande, Puerto Rico, USA.

[6] Choi S.U.S. (1995) 'Enhancing thermal conductivity of fluids with nanoparticles', ASME Fluids Eng Division, 231, 99-105.

[7] Anoop, K.B., Sundararajan, T., Das, S. K. (2009) 'Effect of particle size on the convective heat transfer in nanofluid in the developing region', Int. J. Heat and Mass Transfer, Vol. 52, pp.2189- 2195, (2009).

[8] Khanafer, K., Vafai, K., Lightstone, M. (2003) 'Buoyancydriven heat transfer enhancement in a two-dimensional enclosure utilizing nanofluids', Int. J. Heat Mass Transfer, 46, 3639-3653.

[9] Abu-Nada, E. (2008) 'Application of nanofluids for heat transfer enhancement of separated flow encountered in a backward facing step', Int. J. Heat Fluid Flow, 29, 242-249.

[10] Mutuku-Njane, W. N., Makinde, O. D. (2014) 'MHD nanofluid flow over a permeable vertical plate with convective heating', Journal of Computational and Theoretical Nanoscience, 11(3), 667-675.

[11] Grosan, T., Pop, I. (2012) 'Fully developed mixed convection in a vertical channel filled by a nanofluid', J. Heat Transfer, Vol. 134, 082501-1.

[12] Bejan, A. (1982) Entropy generation through heat and fluid flow, New York: Wiley.

[13] Bejan, A. (1996) Entropy Generation Minimization, CRC, Boca Raton, NY.

[14] Woods, L. C. (1975) 'Thermodynamics of Fluid Systems', Oxford University Press, Oxford, 
[15] Makinde, O. D., Aziz, A. (2010) 'Second law analysis for a variable viscosity plane Poiseuille flow with asymmetric convective cooling', Computers and Mathematics with Applications, 60, 3012-3019.

[16] Makinde, O. D. (2008) 'Entropy generation analysis for variable-viscosity channel flow with nonuniform wall temperature', Appl. Energy, 85 (5), 384-393.

[17] Shahi, M., Mahmoudi, A. H., Honarbakhsh, R. A. (2011) 'Entropy generation due to natural convection cooling of a nanofluid', Int Commun Heat Mass Transfer, 38, 972-83.

[18] Mahmoudi, A. H., Shahi, M., Talebi, F. (2012) 'Entropy generation due to natural convection in a partially open cavity with a thin heat source subjected to a nanofluid', Numer Heat Transfer A, 61, 283-305.
[19] Makinde, O. D., Khan, W. A., Aziz, A. (2013) 'On inherent irreversibility in Sakiadis flow of nanofluids', International Journal of Exergy, 13(2), 159-174.

[20] Mkwizu, M.H., Makinde, O.D. (2015) 'Entropy generation in a variable viscosity channel flow of nanofluids with convective cooling', Comptes Rendus Mecanique 343 38-56.

[21] Maxwell, J. C. (1904) 'A treatise on electricity and magnetism', $2^{\text {nd }}$ ed. Cambridge: Oxford University Press, 435-41.

[22] Brinkman, H. C. (1952) 'The viscosity of concentrated suspensions and solutions', J. Chem. Phys. 20, 571-581.

[23] Na, T. Y. (1979) 'Computational methods in engineering boundary value problems’, Academic press, New York. 